\title{
Parallel Assessment of Bone Mineral Density and RANKL/OPG Ratio in Saudi Females

\author{
AI Hassan ${ }^{1,2}$, SA Eltarhouny ${ }^{3,4}$, HE Hashem ${ }^{1,5}$, SA Algaidi ${ }^{1}$, AR Abdallah ${ }^{6}$, AM Sandokji ${ }^{7}$
}

\begin{abstract}
Background: Osteoporosis is a significant risk factor for morbidity, and its high prevalence among Saudi women should be considered to be a public health problem. Quantitative ultrasound was recommended for bone mineral density (BMD) screening. Receptor activator of nuclear factor kappa$B$ ligand (RANKL) and osteoprotegerin (OPG) and their ratio are critical for physiological bone remodelling, and related abnormalities may lead to several osteopathies.

Methods: The BMD of 499 Saudi females aged 20 to 65 years was measured using quantitative ultrasound from the beginning of October 2013 to the end of March 2014 at the female medical unit of Taibah University, Madinah, KSA. Possible associated risk factors for low BMD were studied. Blood RANKL and OPG were measured by enzyme-linked immunosorbent assay (ELISA).

Results: No significant differences were found between participants with normal and low BMD regarding the studied risk factors. However, there was a significant association $(\mathrm{p}<0.05)$ between $B M D$ and regular physical activity among participants aged 20 years to less than 35 years, and women aged 35-50 years with higher body mass index (BMI) had higher BMD. The RANKL/OPG ratio was inversely associated $(\mathrm{p}=0.04)$ with $B M D$.

Conclusions: Regular physical activity is crucial for maximizing BMD in young females and decreasing the possibility of developing osteoporosis with ageing. The RANKL/OPG ratio might be considered a useful and easy-to-use tool for the prediction of low BMD.
\end{abstract}

Keywords: Bone density, female, osteoprotegerin, quantitative ultrasound, RANKL, Saudi Arabia

WIMJ Open 2016; 3 (1): 1

\section{INTRODUCTION}

Osteoporosis is a significant risk factor for morbidity and markedly diminishes the quality of life of women after menopause $(1,2)$. However, it has been reported that the full achievement of peak bone mass might be reduced in young adulthood due to several conditions such as dieting, low calcium intake, smoking, oligomenorrhoea, excessive alcohol intake, low body mass index, previous fragility

From: ${ }^{1}$ Anatomy Department, Faculty of Medicine, Taibah University, Saudi Arabia, ${ }^{2}$ Anatomy Department, Faculty of Medicine, Cairo University, Egypt, ${ }^{3}$ Biochemistry Department, Faculty of Medicine, Taibah University, Saudi Arabia, ${ }^{4}$ Biochemistry Department, Faculty of Medicine, Zagazig University, Egypt, ${ }^{5}$ Histology and Cell Biology Department, Faculty of Medicine, Zagazig University, Egypt, ${ }^{6}$ Public Health and Community Medicine Department, National Liver Institute, Menoufia University, Egypt and ${ }^{7}$ Orthopaedic Department, Faculty of Medicine, Taibah University, Saudi Arabia.

Correspondence: Dr AR Abdallah, 10 Behga Youssef St, Quesna, Menoufia, Egypt. E-mail: ayat_dr2003@yahoo.com fracture, parental history of hip fracture, chronic obstructive pulmonary disease and glucocorticoid therapy (2-4).

Bone mineral density (BMD) is the amount of bone mineral per unit volume or per unit area. Several medications have recently been labelled for the treatment of osteoporosis, but prevention is preferable to treatment because no therapy fully restores lost bone mass (1). Bone densitometry is used to assess the severity of bone loss, to provide diagnostic criteria and prognostic information on the probability of future fractures and to identify those who need therapy and follow up $(5,6)$. A wide variety of techniques is available to assess BMD and all are applied to the appendicular skeleton and the spine (7). The dual energy Xray absorptiometry (DXA) scan is the most commonly used test for measuring BMD (8). However, DXA is not an optimal tool for population screening, and the International Quantitative Ultrasound Consensus has recommended quantitative ultrasound to screen bone status in the community because it is a noninvasive and less time- 
consuming method that relies on a relatively inexpensive, radiation-free, portable device (9). It has been shown that calcaneal BMD may help to predict bone fractures (10-12).

Bone quality is affected by many factors, including the degree of mineralization, connectivity of bony trabeculae, quality of collagen fibres and health of bone cells (osteoblasts, osteoclasts and osteocytes). Osteoblasts are responsible for continual bone renewal, repair and replacement. Osteoclasts are the only cells capable of bone resorption, a process required for both normal bone homeostasis and pathological bone loss (13). It has been estimated that approximately $10 \%$ of the total bone mass in humans is remodelled each year to maintain bone strength in response to hormonal regulation and mechanical stress (14). An imbalance between bone formation and resorption is thought to underlie the pathogenesis of reduced bone mass in osteoporosis or osteopaenia [which refers to BMD that is lower than normal peak BMD but not low enough to be classified as osteoporosis] (15). Hence, it has been suggested that inhibition of bone remodelling should become a major therapeutic strategy for preventing bone loss (16).

Bone resorption was reported to be dependent on a cytokine known as receptor activator of nuclear factor kappaB ligand (RANKL), which is balanced by osteoprotegerin [OPG] (Fig. 1).

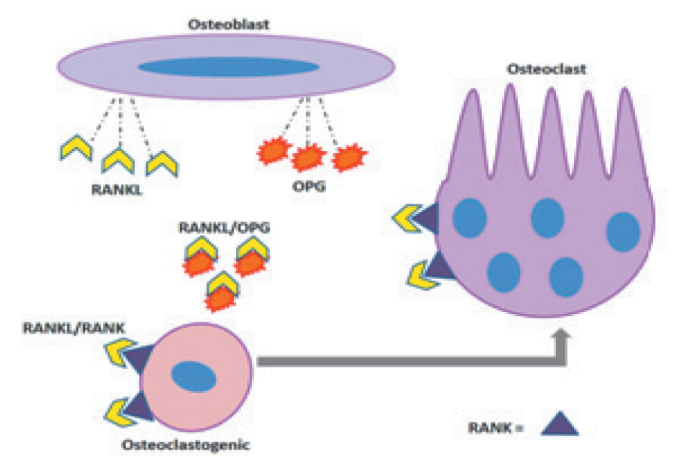

Fig. 1: The regulatory action of osteoprotegerin (OPG) and receptor activator of nuclear factor kappa-B ligand (RANKL) on progenitor and mature osteoclasts.

Receptor activator of nuclear factor kappa-B ligand is a tumour necrosis factor (TNF) family member produced and secreted by osteoblasts, which, through binding to its receptor (RANK) on progenitor and mature osteoclasts, regulates osteoclastogenesis and activation of osteoclasts in normal and pathological states of bone remodelling $(17,18)$. Osteoprotegerin is a "protector of the bone" TNF receptor family member produced by osteoblasts that binds to RANKL and thereby blocks the RANKL-RANK interaction, inhibiting differentiation and activation of the osteoclasts (19), as illustrated in Fig. 1. The RANKL/OPG ratio is critical for physiological bone remodelling and should enable sufficient assessment of osteoblast-induced stimulus of osteoclasts. Abnormalities in the RANKL/OPG ratio may lead to several osteopathies $(20,21)$.

A high prevalence of postmenopausal osteoporosis was reported in Saudi women in different areas in Saudi Arabia and should be considered a public health problem (5). However, there is a paucity of prospective studies on screening and treatment in younger age groups, so few practice recommendations exist to guide the management of osteoporosis in young adults $(3,22)$.

Therefore, this study was conducted to measure the BMD of apparently healthy Saudi females aged 20-65 years using an easy, simple, and non-invasive quantitative ultrasound method and identify possible associated risk factors for osteopaenia or osteoporosis among them. The study was extended to measure blood RANKL and OPG among participants by enzyme-linked immunosorbent assay (ELISA) to assess the relationship between BMD and the RANKL/OPG ratio. This might be helpful in early diagnosis of those with low BMD to establish proper control and prevention of future osteoporosis among Saudi women.

\section{SUBJECTS AND METHODS}

This cross-sectional study was conducted among 499 Saudi females from the beginning of October 2013 to the end of March 2014 at the female medical unit, Taibah University, Madinah, Saudi Arabia.

The study was performed in compliance with the Helsinki Declaration and in accordance with the regulations laid down by the Taibah University Ethical Committee. Written informed consent was obtained from all participants prior to their participation in the study.

\section{Inclusion and exclusion criteria}

All apparently healthy Saudi female students, staff members, and employees 20-65 years old and attending Taibah University main campus were invited to participate in the study either during University social events or in response to advertisements at different colleges. A total of 509 participants were recruited. However, those with one or more of the following criteria were excluded from the study: primary or secondary amenorrhea, thyroid diseases, chronic illness, or using medications that can affect bone density (eg corticosteroids, vitamin D and calcium). Ten participants were excluded from the study.

Data were collected using the following tools:

\section{Questionnaire}

A paper-based questionnaire was distributed to all participants. It contained questions on sociodemographic data (eg age, marital status, perceived family social standard, number of children and education level), possible risk factors of osteoporosis (eg family history of osteoporosis or fracture), lifestyle data (sedentary behaviours, regular physical activity, walking for 30 minutes three times a week, diet (dairy 
consumption) and sun exposure) and medical history including any chronic diseases or medications. This questionnaire was used in a previous study conducted in Saudi Arabia (23).

\section{Measurement of weight and height and calculation of body mass index}

The weight and height of participants were measured at the university's medical unit, and body mass index (BMI) was calculated using the following equation: $\mathrm{BMI}=$ weight $(\mathrm{kg}) /$ height $(\mathrm{m})^{2}$. Participants with BMI $<18.5$ were considered to be underweight, those with BMI ranging from 18.524.9 were considered normal weight, those with BMI ranging from 25.0-29.9 were considered overweight, and finally those with BMI $\geq 30.0$ were considered obese (24).

\section{Bone mineral density measurement}

Bone mineral density measurement was performed on one leg for all the participants by the quantitative ultrasound technique with the subject in a sitting position using the water-based Achilles InSight ultrasonometer (GE Healthcare). The heel of the non-dominant leg was placed between two ultrasonic transducers in a water bath at $37{ }^{\circ} \mathrm{C}$. The ultrasound uses high-frequency sound waves to measure the heel bone mineral density. The patient's result is expressed as a T-score and Z-score and is graphed against the reference population. Measurement results are displayed, stored and printed including measurement values and fracture risk colour graphs for easy clinical assessment and visual communication for the patient. The T-score compares the subject's BMD to the mean value in a healthy, young reference population $(3,22)$, while the $\mathrm{Z}$-score compares the subject's BMD to the age-matched population. In this study, we used the T-score because it is considered to provide the best information on the extent of bone loss (25). According to the brochure for the Achilles InSight system, participants were classified into three groups according to their T-score: group I: participants with normal bone density (T-score $>-1$ ), group II: participants with osteopaenia (T-score ranging from -1 to -2.5 ) and group III: participants with osteoporosis (Tscore $<-2.5$ ).

\section{Blood sample collection}

Blood samples from participants were drawn by venipuncture in the morning in completely aseptic conditions by puncture of an antecubital vein. Samples were left in a plain tube for 30-60 minutes to allow spontaneous clotting at room temperature then centrifuged at $3000 \mathrm{rpm}$ for 10 minutes for serum separation. The obtained sera were frozen immediately at $-70{ }^{\circ} \mathrm{C}$ for future analysis, and the total serum levels of RANKL and OPG in the samples were determined by ELISA using a commercial kit (BioVendor $\mathrm{GmbH}$, Heidelberg Germany and Immundiagnostik AG, Stubenwald, Germany, respectively) using horseradish peroxidase detec- tion in accordance with the manufacturer's instructions. Samples $(100 \mu \mathrm{L})$ were assayed in duplicate. The ratio of the serum levels of RANKL and OPG (RANKL/OPG ratio) was also calculated.

\section{Statistical analysis}

The obtained data were collected and entered into the computer using SPSS (Statistical Package for Social Sciences) programme, version 17 (SPSS Inc, Chicago, IL, USA). the following two types of statistics were performed:

- Descriptive statistics: quantitative data are shown as the mean and standard deviation (SD), while qualitative data are expressed as frequency and per cent.

- Analytical statistics: the Chi-squared test was used to measure the association between qualitative variables, while the Mann-Whitney test was used to compare the mean ranks of two sets of quantitative, not normally distributed data. A $p$-value was considered statistically significant when at less than 0.05 .

\section{RESULTS}

A total of 499 Saudi females with a mean age of 31.87 ( \pm $0.33)$ years participated in this study. More than two-thirds $(66.7 \%)$ were between 20 and 35 years old. The majority (85.4\%) had higher education (including participating undergraduate students). Normal weight and obese participants were common, with similar percentages among participants (36.9\% and $33.3 \%$, respectively), and only $1 \%$ was diagnosed as osteoporotic based on their T-score (Table $1)$.

\section{Association between BMD and risk factors for low BMD} Table 2 shows the risk factors for low BMD among the participants. Due to the small number of participants in the osteoporotic group, the data from osteoporotic and osteopaenic participants were merged and considered as one group with low BMD (T-score $\leq 1$ ). No significant differences were found between the normal and low BMD group for any of the studied risk factors $(p>0.05)$. However, regular physical activity was higher in the normal BMD group than the low BMD group $(49.9 \%$ vs $40.7 \%)$. We found no participant who consumed more than two cups of milk products/day with low BMD. More than one-third of the participants in both groups did not consume milk products daily ( $41.4 \%$ and $41.9 \%)$.

Because $66.7 \%$ of our participants ranged from 20 to less than 35 years, they constituted $59.3 \%$ of those with low BMD. However, low BMD was present in $30 \%$ of participants more than 50 years old compared to only $15.3 \%$ of the participants aged 20 years to 34 years old (Table 1, Table 2 and Fig. 2). 
Table 1: Description of participants' characteristics

\begin{tabular}{|c|c|c|}
\hline Variables & $\begin{array}{c}\text { Number } \\
(\text { total }=499)\end{array}$ & Per cent \\
\hline \multicolumn{3}{|l|}{ Age (years) } \\
\hline $20-34$ & 333 & 66.7 \\
\hline $35-50$ & 136 & 27.3 \\
\hline$>50$ & 30 & 6.0 \\
\hline \multicolumn{3}{|l|}{ Marital status } \\
\hline Ever married & 292 & 58.5 \\
\hline Never married & 207 & 41.5 \\
\hline \multicolumn{3}{|l|}{ Number of children } \\
\hline $0-2$ & 351 & 70.3 \\
\hline $3-6$ & 130 & 26.1 \\
\hline$>6$ & 18 & 3.6 \\
\hline \multicolumn{3}{|l|}{ Education } \\
\hline Higher education & 462 & 85.4 \\
\hline Secondary school & 60 & 12.0 \\
\hline Primary education & 7 & 1.4 \\
\hline Illiterate & 5 & 1.2 \\
\hline \multicolumn{3}{|c|}{ Perceived socio-economic status } \\
\hline High & 173 & 34.7 \\
\hline Moderate & 280 & 56.1 \\
\hline Low & 46 & 9.2 \\
\hline \multicolumn{3}{|l|}{ Body mass index } \\
\hline Underweight & 31 & 6.2 \\
\hline Normal & 184 & 36.9 \\
\hline Overweight & 118 & 23.6 \\
\hline Obese & 166 & 33.3 \\
\hline \multicolumn{3}{|l|}{ T-score } \\
\hline Normal & 413 & 82.8 \\
\hline Osteopaenia & 81 & 16.2 \\
\hline Osteoporosis & 5 & 1.0 \\
\hline
\end{tabular}

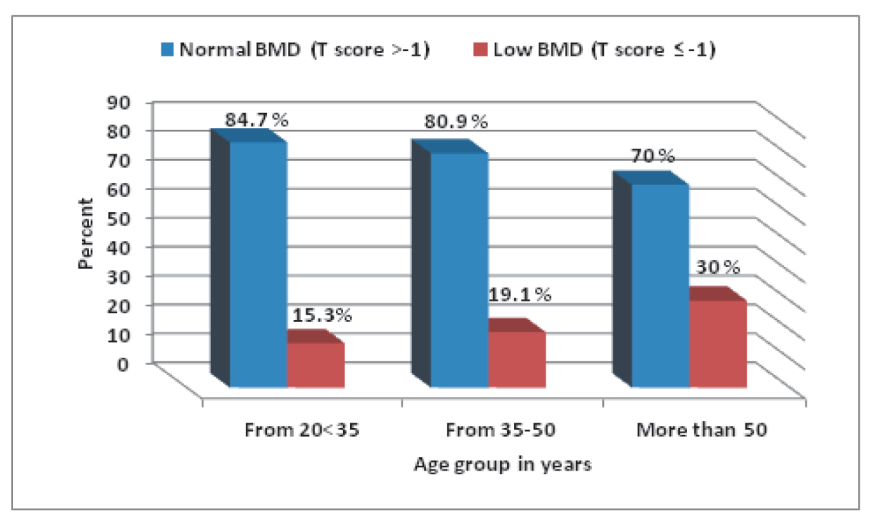

Fig. 2: Prevalence of low bone mineral density (BMD: osteopaenia and osteoporosis) among participants distributed by their age group.

\section{Association between age, dietary and behavioural habits, and low BMD}

A significant association $(p<0.05)$ was found between BMD and regular physical activity (walking for 30 minutes three times a week) among participants aged 20 years to less than 35 years old. We found that more than half of those with normal BMD (52.5\%) reported engaging in regular physical activity compared to $35.3 \%$ of those with low BMD (Table $3)$. Additionally, a significant difference $(p<0.05)$ was found between BMD and BMI among participants 35-50 years old. Obesity was higher among those with normal BMD than those with low BMD [56.4\% vs 30.8\%] (Table 4).

Table 2: Risk factors for low bone mineral density (osteopaenia and osteoporosis) among participants

\begin{tabular}{|c|c|c|c|c|c|}
\hline \multirow[t]{2}{*}{ Variables } & \multicolumn{2}{|c|}{$\begin{array}{l}\text { Group I } \\
(n=413)\end{array}$} & \multicolumn{2}{|c|}{$\begin{array}{c}\text { Group II } \\
(\mathrm{n}=86)\end{array}$} & \multirow[t]{2}{*}{$p$-value } \\
\hline & n & $\%$ & $\mathbf{n}$ & $\%$ & \\
\hline \multicolumn{6}{|l|}{ Age (years) } \\
\hline $20-34$ & 282 & 68.3 & 51 & 59.3 & \\
\hline $35-50$ & 110 & 26.6 & 26 & 30.2 & 0.099 \\
\hline$>50$ & 21 & 5.1 & 9 & 10.5 & \\
\hline \multicolumn{6}{|l|}{ Marital status } \\
\hline Ever married & 240 & 58.1 & 52 & 60.5 & 0.687 \\
\hline Never married & 173 & 41.9 & 34 & 39.5 & \\
\hline \multicolumn{6}{|l|}{ Number of children } \\
\hline $0-2$ & 292 & 70.7 & 59 & 68.6 & \\
\hline $3-6$ & 105 & 25.4 & 25 & 29.1 & 0.644 \\
\hline$>6$ & 16 & 3.9 & 2 & 2.3 & \\
\hline \multicolumn{6}{|l|}{ Education } \\
\hline Higher education & 356 & 86.2 & 70 & 81.4 & \\
\hline Secondary school & 47 & 11.4 & 13 & 15.1 & 0.072 \\
\hline Primary education & 7 & 1.7 & 0 & 0.0 & \\
\hline Illiterate & 3 & 0.7 & 3 & 3.5 & \\
\hline \multicolumn{6}{|c|}{ Perceived socio-economic status } \\
\hline High & 140 & 33.9 & 33 & 38.4 & \\
\hline Moderate & 234 & 56.7 & 46 & 53.5 & 0.715 \\
\hline Low & 39 & 9.4 & 7 & 8.1 & \\
\hline \multicolumn{6}{|c|}{ History of daily intake of milk products } \\
\hline No & 171 & 41.4 & 36 & 41.9 & \\
\hline One cup & 210 & 50.8 & 45 & 52.3 & 0.727 \\
\hline Two cups & 26 & 6.3 & 5 & 5.8 & \\
\hline More than two cups & 6 & 1.5 & 0 & 0.0 & \\
\hline \multicolumn{6}{|c|}{ History of daily sun exposure } \\
\hline Yes & 283 & 68.5 & 53 & 61.6 & 0.215 \\
\hline No & 130 & 31.5 & 33 & 38.4 & \\
\hline
\end{tabular}


Table 2 (Cont'd): $\quad$ Risk factors for low bone mineral density (osteopaenia and osteoporosis) among participants

\begin{tabular}{lrrrrr}
\hline \multicolumn{1}{c}{ Variables } & \multicolumn{2}{c}{$\begin{array}{c}\text { Group I } \\
(\mathbf{n}=\mathbf{4 1 3})\end{array}$} & \multicolumn{2}{c}{$\begin{array}{c}\text { Group II } \\
(\mathbf{n}=\mathbf{8 6})\end{array}$} & p-value \\
& $\mathbf{n}$ & $\mathbf{\%}$ & $\mathbf{n}$ & $\mathbf{\%}$ & \\
\hline History of regular physical activity & & & & & \\
Yes & 206 & 49.9 & 35 & 40.7 & 0.121 \\
No & 207 & 50.1 & 51 & 59.3 & \\
Family history of osteoporosis & 131 & 31.7 & 20 & 23.3 & 0.120 \\
Yes & 282 & 68.3 & 66 & 76.7 & \\
No & & & & & \\
Body mass index & 25 & 6.1 & 6 & 7.0 & 0.251 \\
Underweight & 145 & 35.1 & 39 & 45.3 & \\
Normal & 103 & 24.9 & 15 & 17.4 & \\
Overweight & 140 & 33.9 & 26 & 30.2 & \\
Obese & & & & &
\end{tabular}

Group I: participants diagnosed as having normal bone density by bone mineral density (T-score $>-1$ ) Group II: participants diagnosed as having osteopaenia/osteoporosis by bone mineral density (T-score $\leq-1)$

Table 3: Association of RANKL, OPG and T-score among participants

\begin{tabular}{lccc}
\hline Variables & $\begin{array}{c}\text { Group I } \\
\text { Mean } \pm \text { SD }\end{array}$ & $\begin{array}{c}\text { Group II } \\
\text { Mean } \pm \text { SD }\end{array}$ & $\boldsymbol{p}$-value \\
\hline RANKL & $529.60 \pm 671.54$ & $428.33 \pm 468.41$ & 0.880 \\
OPG & $685.26 \pm 422.036$ & $579.19 \pm 536.630$ & 0.072 \\
Ratio & $1.76 \pm 5.08$ & $1.79 \pm 2.61$ & $0.040^{*}$ \\
\hline
\end{tabular}

*Significant association

RANKL: receptor activator of nuclear factor kappa-B ligand; OPG: osteoprotegerin

Group I: Participants diagnosed as having normal bone density by bone mineral density (T-score $>-1)$

Group II: Participants diagnosed as having osteopaenia/osteoporosis by bone mineral density $(\mathrm{T}$-score $\leq-1)$

\section{Association between RANKL/OPG ratio and T-score}

No significant associations were found between RANKL, OPG and T-score among participants $(p>0.05)$. However, the RANKL/OPG ratio was significantly associated with $\mathrm{T}$ score $[p<0.05]$ (Table 5).

Age, history of regular physical activity, BMI and history of daily intake of milk products were not independently associated with RANKL/OPG ratio when introduced in a linear regression model $(p>0.05)$.

Table 4: Dietary and behavioural risk factors of low bone mineral density (BMD: osteopaenia and osteoporosis) among participants aged 20 to 34 years

\begin{tabular}{lrrrrr}
\hline \multicolumn{1}{c}{ Variables } & \multicolumn{2}{c}{$\begin{array}{c}\text { Group I } \\
(\mathbf{n}=\mathbf{2 8 2})\end{array}$} & \multicolumn{2}{c}{$\begin{array}{c}\text { Group II } \\
(\mathbf{n}=\mathbf{5 1})\end{array}$} & p-value \\
& \multicolumn{1}{c}{$\mathbf{n}$} & $\mathbf{\%}$ & $\mathbf{n}$ & $\mathbf{\%}$ & \\
\hline History of daily intake of milk products & & & & & \\
No & 124 & 44.0 & 22 & 43.2 & 0.662 \\
One cup & 134 & 47.5 & 27 & 52.9 & \\
Two cups & 21 & 7.4 & 2 & 3.9 & \\
More than two cups & 3 & 1.1 & 0 & 0.0 & \\
History of daily sun exposure & & & & & \\
Yes & 207 & 73.4 & 34 & 66.7 & 0.322 \\
No & 75 & 26.6 & 17 & 33.3 & \\
History of regular physical activity & & & & & \\
Yes & 148 & 52.5 & 18 & 35.3 & $0.024^{*}$ \\
No & 134 & 47.5 & 33 & 64.7 & \\
Body mass index & & & & & \\
Underweight & 20 & 7.1 & 6 & 11.8 & 0.086 \\
Normal & 130 & 46.1 & 29 & 56.9 & \\
Overweight & 70 & 24.8 & 5 & 9.8 & \\
Obese & 62 & 22.0 & 11 & 21.5 & \\
\hline
\end{tabular}

*Significant association

Group I: participants diagnosed as having normal bone density by bone mineral density (T-score $>-1$ ) Group II: participants diagnosed as having osteopaenia/osteoporosis by bone mineral density (T-score $\leq-1)$ 
Table 5: Dietary and behavioural risk factors of low bone mineral density (BMD: osteopaenia and osteoporosis) among participants aged 35 to 50 years

\begin{tabular}{|c|c|c|c|c|c|}
\hline \multirow[t]{2}{*}{ Variables } & \multicolumn{2}{|c|}{$\begin{array}{c}\text { Group I } \\
(\mathrm{n}=110)\end{array}$} & \multicolumn{2}{|c|}{$\begin{array}{c}\text { Group II } \\
(\mathrm{n}=26)\end{array}$} & \multirow[t]{2}{*}{$p$-value } \\
\hline & n & $\%$ & n & $\%$ & \\
\hline \multicolumn{6}{|c|}{ History of daily intake of milk products } \\
\hline No & 41 & 37.3 & 12 & 46.2 & 0.620 \\
\hline One cup & 64 & 58.2 & 13 & 50.0 & \\
\hline Two cups & 2 & 1.8 & 1 & 3.8 & \\
\hline More than two cups & 3 & 2.7 & 0 & 0.0 & \\
\hline \multicolumn{6}{|c|}{ History of daily sun exposure } \\
\hline Yes & 63 & 57.3 & 14 & 53.8 & 0.751 \\
\hline No & 47 & 42.7 & 12 & 46.2 & \\
\hline \multicolumn{6}{|c|}{ History of regular physical activity } \\
\hline Yes & 47 & 42.7 & 11 & 42.3 & 0.969 \\
\hline No & 63 & 57.3 & 15 & 57.7 & \\
\hline \multicolumn{6}{|l|}{ Body mass index } \\
\hline Underweight & 5 & 4.5 & 0 & 0.0 & $0.011^{*}$ \\
\hline Normal & 15 & 13.6 & 10 & 38.4 & \\
\hline Overweight & 28 & 25.5 & 8 & 30.8 & \\
\hline Obese & 62 & 56.4 & 8 & 30.8 & \\
\hline
\end{tabular}

*Significant association

Group I: participants diagnosed as having normal bone density by bone mineral density (T-score $>-1$ ) Group II: participants diagnosed as having osteopaenia/osteoporosis by bone mineral density (T-score $\leq-1)$

\section{DISCUSSION}

Clinical data indicate that osteoporosis is the main cause of pathological fractures in older adults, leading to disability and death (26). In the current work, quantitative ultrasound was used to measure BMD, which has been recommended for screening bone status in the community by the International Quantitative Ultrasound Consensus (9). Of all the available techniques for peripheral testing of BMD, heel ultrasound has significant advantages over other peripheral devices because it is easy to use, is an excellent predictor of hip and spine fracture, and avoids the use of ionizing radiation. The Achilles InSight used in the current work used a real-time image of the heel for confident positioning and accurate measuring $(9,27)$. Dual energy X-ray absorptiometry and quantitative ultrasound are both useful for detecting bone demineralization in patients with thalassaemia (28). In the quantitative ultrasound method, the calcaneus was chosen for the measurement of bone density because the calcaneus bone encompasses a large volume of trabecular bone between relatively flat faces and is readily accessible for transmission measurements. The use of the nondominant leg to measure BMD in the present study was chosen based on the suggestion that the mechanical loading on the bone of the dominant leg might result in an increase in bone mass to accommodate the greater load and so lead to a false impression of general BMD (9).

In the current study, $30 \%$ of women above 50 years had a T-score of -1 or lower (osteopaenic/osteoporotic). This prevalence of osteopaenia and osteoporosis is much lower than that reported by other Saudi studies conducted in Riyadh [57.7\%] (5) and eastern Saudi Arabia [76\%] (29), which used dual X-ray absorptiometry. This difference could be attributed to several factors such as the different methods used to assess BMD, the different sites of measurement (lumbar spine and upper femur), and the different dietary and behavioural habits in different areas of Saudi Arabia. Additionally, it has been reported that the atmosphere in urban Riyadh is saturated with dust particles and vehicle pollution, which may affect the availability of ultraviolet radiation because the dust is composed of mineral particles that both absorb and scatter sunlight and might therefore affect vitamin D synthesis (30).

The study results showed that $15 \%$ of participants between 20 years and 35 years old showed low bone density, which contradicts other studies (31) that reported that continuous physiologic bone loss of human skeleton starts at approximately age 35 years and continues at different rates throughout life. However, the present study did not find any significant association between the low BMD observed in this age group (20 years to less than 35 years) and the studied risk factors except for regular physical activity. This result is consistent with the findings of other studies, which reported that physical activity is vital in adults because it reduces the rate of bone loss during the perimenopausal period and decelerates bone loss associated with ageing $(32,33)$.

The current study did not find any association between daily milk/milk product consumption and low BMD in any age group. However, more than one-third of participants in the normal and low BMD groups do not consume daily milk products at all. It is worth mentioning that none of our participants who consumed near the daily requirement of dairy products (more than two cups of dairy products) had 
low BMD. It has been reported that calcium intake has no effect on quantitative ultrasound measurements at the heel, and systematic physical activity and adequate dietary calcium intake are recommended for women as a means to maximize bone status benefits (9). However, other studies investigated the role of calcium on bone mass and concluded that calcium has a positive effect on bone mass throughout life and is an important nutritional factor for bone health (34). Fifteen minutes of sunlight exposure daily is recommended to maintain adequate vitamin D stores (35). In the current study, participants who do not expose their hands and face and/or use sun block during the daytime were considered as lacking exposure to sunlight. In Saudi Arabia, the majority of females cover their heads and faces due to cultural and religious practices. However, these study participants could be considered moderately exposed to sunlight; all of them were either studying or working at the Taibah University female campus without covering their heads or faces. No significant association has been found between low BMD and sun exposure. Some studies have attributed the high prevalence of osteomalacia and vitamin D deficiencies in Saudi Arabian women to their cultural practice of wearing clothing that covers the entire body and face, which could prevent direct exposure to sunlight $(30,36)$. Other Saudi studies also found a direct positive correlation between sun exposure and serum levels of vitamin D (37). It has been suggested that solar ultraviolet B irradiation is the primary source of vitamin $\mathrm{D}$ (other than dietary supplements) for most people because dietary sources of vitamin $\mathrm{D}$ are limited. Vitamin D plays a central role in calcium and phosphorus homeostasis and skeletal health (38). Impaired calcium metabolism due to low serum $25(\mathrm{OH}) \mathrm{D}$ levels triggers secondary hyperparathyroidism, increased bone turnover and progressive bone loss (38). Some studies concluded that vitamin D deficiency is common among Saudi children and adolescents, and it is influenced by both sun exposure and physical activity (39). This might explain the significant association between physical activity and BMD found in the present study because these participants might also have higher levels of vitamin $\mathrm{D}$ and hence higher BMD.

In the current study, a significant difference $(p<0.05)$ was found between BMD and BMI among participants 3550 years old. Interestingly, obesity was higher among the normal BMD group than the low BMD group (56.4\% vs $30.8 \%$ ). This is consistent with other studies (40) that reported that increasing weight and BMI are associated with higher bone density. It is suggested that a larger body mass imposes a greater mechanical loading on bone that results in an increase in bone mass to accommodate the greater load (9). It has been proposed that the increase in adipose tissue that occurs with increasing BMI in postmenopausal women results in increased oestrogen production, osteoclast suppression and a resultant increase in bone mass. In addition, obesity has a protective effect on bone through several mechanisms such as increased aromatization of androgen to oestrogen in adipose tissue (41) and decreased sex-hormone binding globulin with a corresponding increase in free sex steroids (40). However, it has been reported that insulin resistance induced by a 12-week high-fat diet resulted in osteoporosis in the jawbone (42).

The RANKL/OPG ratio was significantly associated with T-score among the studied population $(p<0.05)$, although no significant association was found between RANKL, OPG and T-score $(p>0.05)$. Receptor activator of nuclear factor kappa-B ligand was reported to be the unique osteoclastogenesis cytokine promoting osteoclast formation $(17,18,43)$. It has been suggested that osteoclast functional activity rather than formation is increased in primary osteoporosis and that dexamethasone acts to increase osteoclast formation (15). Oestrogen therapy was reported to have a significant antiresorptive effect through its enhancing effect on the osteoblastic production of OPG, which has antiosteoclastic properties because of its ability to bind to RANKL and subsequently to block the RANKL/RANK interaction required for osteoclast recruitment and activation (44). The suppression of bone remodelling in normal rats by OPG was reported to increase bone volume and density, and the stimulation of bone remodelling in normal mice or rats by RANKL leads to reduced bone volume (45). Additionally, studies in numerous animal models of bone disease showed that RANKL inhibition and injection of antimouse RANKL antibody lead to marked suppression of bone resorption and increases in cortical and cancellous bone volume, density and strength. It also significantly prevented alveolar bone loss in OPG-deficient mice (46). Receptor activator of nuclear factor kappa-B ligand inhibitors prevent the focal bone loss that occurs in animal models of rheumatoid arthritis and bone metastasis (16). In addition, deregulation of RANK signalling restraining increased the formation of hyper-resorptive osteoclasts and prevented osteoporotic deficits (47). A positive influence of exercise on RANK/RANKL/OPG pathway in bone metabolism has also been suggested (48).

\section{LIMITATIONS}

The results of this study cannot be generalized to all females in all the provinces of Saudi Arabia due to differences in behavioural and dietary habits. Data on sun exposure, physical activity and dairy consumption were based on questionnaires that are subject to recall bias.

\section{CONCLUSIONS}

The prevalence of low BMD in apparently healthy nonsymptomatic working females aged over 50 years in $\mathrm{Al}$ Madinah city is less than that recorded in females of the same age in other provinces of Saudi Arabia. The high prevalence of low BMD in the young age group (20 years to less than 35 years) and the significant effect of regular physical activity on BMD should raise awareness of the importance of regular physical activity to maximize BMD in young females and thus decrease the possibility of developing osteoporosis with 
ageing. Measurement of OPG and RANKL and use of the RANKL/OPG ratio is recommended to be further investigated as a useful, easy to use tool for the prediction of low BMD.

\section{ACKNOWLEDGEMENTS}

Great thanks to all the participants who agreed to participate in this research. We would like to extend our thanks and appreciation to The Deanship of Scientific Research, Taibah University, Saudi Arabia, for supporting this project with grant no. $433 / 807$.

\section{REFERENCES}

1. Keramat A, Patwardhan B, Larijani B, Chopra A, Mithal A, Chakravarty $\mathrm{D}$ et al. The assessment of osteoporosis risk factors in Iranian women compared with Indian women. BMC Musculoskelet Disord 2008; 9: 28

2. Graat-Verboom L, Spruit MA, van den Borne BE, Smeenk FW, Wouters EF. Whole-body versus local DXA-scan for the diagnosis of osteoporosis in COPD patients. J Osteoporos 2010; 2010: 640878.

3. Gourlay ML, Brown SA. Clinical considerations in premenopausal osteoporosis. Arch Intern Med 2004; 164: 603-14.

4. Kanis JA, Oden A, Johnell O, Johansson H, De Laet C, Brown J et al. The use of clinical risk factors enhances the performance of BMD in the prediction of hip and osteoporotic fractures in men and women. Osteoporos Int 2007; 18: 1033-46.

5. El-Desouki MI. Osteoporosis in postmenopausal Saudi women using dual x-ray bone densitometry. Saudi Med J 2003; 24: 953-6.

6. Kanis JA, Reginster JY. European guidance for the diagnosis and management of osteoporosis in postmenopausal women - what is the current message for clinical practice? Pol Arch Med Wewn 2008; 118: 538-40.

7. Engelke K, Gluer CC. Quality and performance measures in bone densitometry: part 1: errors and diagnosis. Osteoporos Int 2006; 17: 1283-92.

8. World Health Organization. Prevention and management of osteoporosis. Report of a WHO Scientific Group. WHO Technical Report Series 921. Geneva: WHO; 2003: 1-164, back cover.

9. Dionyssiotis Y, Paspati I, Trovas G, Galanos A, Lyritis GP. Association of physical exercise and calcium intake with bone mass measured by quantitative ultrasound. BMC Womens Health 2010; 10: 12.

10. Xu Y, Guo B, Gong J, Xu H, Bai Z. The correlation between calcaneus stiffness index calculated by QUS and total body BMD assessed by DXA in Chinese children and adolescents. J Bone Miner Metab 2014; 32: $159-66$

11. Muschitz C, Dimai HP, Kocijan R, Kaider A, Zendeli A, Kuhne F et al. The discriminatory capacity of BMD measurements by DXA and dual $\mathrm{X}$-ray and laser (DXL) at the calcaneus including clinical risk factors for detecting patients with vertebral fractures. Osteoporos Int 2013; 24: 2181-90.

12. Brismar TB, Janszky I, Toft LI. Calcaneal BMD obtained by dual Xray and laser predicts future hip fractures - a prospective study on 4398 Swedish women. J Osteoporos 2010; 10: 875647.

13. Novack DV, Teitelbaum SL. The osteoclast: friend or foe? Annu Rev Pathol 2008; 3: 457-84.

14. Gertz ER, Silverman NE, Wise KS, Hanson KB, Alekel DL, Stewart JW et al. Contribution of serum inflammatory markers to changes in bone mineral content and density in postmenopausal women: a 1-year investigation. J Clin Densitom 2010; 13: 277-82.

15. Jevon M, Hirayama T, Brown MA, Wass JA, Sabokbar A, Ostelere S et al. Osteoclast formation from circulating precursors in osteoporosis. Scand J Rheumatol 2003; 32: 95-100

16. Kearns AE, Khosla S, Kostenuik PJ. Receptor activator of nuclear factor kappaB ligand and osteoprotegerin regulation of bone remodeling in health and disease. Endocr Rev 2008; 29: 155-92.
17. Novack DV. Role of NF-kappaB in the skeleton. Cell Res 2011; 21: $169-82$.

18. Novack DV, Faccio R. Osteoclast motility: putting the brakes on bone resorption. Ageing Res Rev 2011; 10: 54-61.

19. Stolina M, Schett G, Dwyer D, Vonderfecht S, Middleton S, Duryea D et al. RANKL inhibition by osteoprotegerin prevents bone loss without affecting local or systemic inflammation parameters in two rat arthritis models: comparison with anti-TNFalpha or anti-IL-1 therapies. Arthritis Res Ther 2009; 11: R187.

20. Bonucci E, Ballanti P. Osteoporosis-bone remodeling and animal models. Toxicol Pathol 2014; 42: 957-69.

21. Corrado A, Neve A, Macchiarola A, Gaudio A, Marucci A, Cantatore FP. RANKL/OPG ratio and DKK-1 expression in primary osteoblastic cultures from osteoarthritic and osteoporotic subjects. J Rheumatol 2013; 40: 684-94.

22. Gourlay M. Osteoporosis management: out of subspecialty practice and into primary care. Am Fam Physician 2004; 70: 1219-20.

23. Al-Nozha MM, Al-Hazzaa HM, Arafah MR, Al-Khadra A, Al-Mazrou YY, Al-Maatouq MA et al. Prevalence of physical activity and inactivity among Saudis aged $30-70$ years. A population-based cross-sectional study. Saudi Med J 2007; 28: 559-68.

24. World Health Organization. Obesity: preventing and managing the global epidemic. WHO Technical Report Series 894. Geneva: WHO; 2000.

25. Cummings SR, Bates D, Black DM. Clinical use of bone densitometry: scientific review. JAMA 2002; 288: 1889-97.

26. Metcalfe D. The pathophysiology of osteoporotic hip fracture. McGill J Med 2008; 11: 51-7.

27. Theodorou SJ, Theodorou DJ, Sartoris DJ. Osteoporosis: a global assessment of clinical and imaging features. Orthopedics 2005; 28: 1346-53; quiz 54-5.

28. Argentiero A, Neglia C, Peluso A, di Rosa S, Ferrarese A, Di Tanna G et al. The ability of lumbar spine DXA and phalanx QUS to detect previous fractures in young thalassemic patients with hypogonadism, hypothyroidism, diabetes, and hepatitis-B: a 2-year subgroup analysis from the Taranto Area of Apulia Region. J Pediatr Hematol Oncol 2013; 35: e260-4.

29. Sadat-Ali M, Al-Habdan IM, Al-Turki HA, Azam MQ. An epidemiological analysis of the incidence of osteoporosis and osteoporosisrelated fractures among the Saudi Arabian population. Ann Saudi Med 2012; 32: 637-41.

30. Sedrani SH. Vitamin D status of Saudi men. Trop Geogr Med 1984; 36: 81-7.

31. Drozdzowska B, Pluskiewicz W, Tarnawska B. Panoramic-based mandibular indices in relation to mandibular bone mineral density and skeletal status assessed by dual energy X-ray absorptiometry and quantitative ultrasound. Dentomaxillofac Radiol 2002; 31: 361-7.

32. Beitz R, Doren M. Physical activity and postmenopausal health. J Br Menopause Soc 2004; 10: 70-4.

33. Asikainen TM, Kukkonen-Harjula K, Miilunpalo S. Exercise for health for early postmenopausal women: a systematic review of randomised controlled trials. Sports Med 2004; 34: 753-78.

34. Heaney RP. Calcium, dairy products and osteoporosis. J Am Coll Nutr 2000; 19 (Suppl): 83S-99S.

35. Lambing CL. Osteoporosis 2003. Proceedings of the American Academy of Family Physicians. Annual Scientific Assembly: 2003 Oct $1-5$; New Orleans, Louisiana.

36. Sedrani SH. Low 25-hydroxyvitamin D and normal serum calcium concentrations in Saudi Arabia: Riyadh region. Ann Nutr Metabolism 1984; 28: 181-5.

37. Siddiqui AM, Kamfar HZ. Prevalence of vitamin D deficiency rickets in adolescent school girls in Western region, Saudi Arabia. Saudi Med J 2007; 28: 441-4

38. Holick MF. High prevalence of vitamin D inadequacy and implications for health. Mayo Clin Proc 2006; 81: 353-73.

39. Al-Othman A, Al-Musharaf S, Al-Daghri NM, Krishnaswamy S, Yusuf DS, Alkharfy KM et al. Effect of physical activity and sun exposure on 
vitamin D status of Saudi children and adolescents. BMC Pediatr 2012; 12: 92 .

40. Albala C, Yanez M, Devoto E, Sostin C, Zeballos L, Santos JL. Obesity as a protective factor for postmenopausal osteoporosis. Int J Obes Relat Metab Disord 1996; 20: 1027-32.

41. Nawata H, Tanaka S, Tanaka S, Takayanagi R, Sakai Y, Yanase T et al. Aromatase in bone cell: association with osteoporosis in postmenopausal women. J Steroid Biochem Mol Biol 1995; 53: 165-74.

42. Pramojanee SN, Phimphilai M, Kumphune S, Chattipakorn N, Chattipakorn SC. Decreased jaw bone density and osteoblastic insulin signaling in a model of obesity. J Dent Research 2013; 92: 560-5.

43. Xiong J, Onal M, Jilka RL, Weinstein RS, Manolagas SC, O’Brien CA Matrix-embedded cells control osteoclast formation. Nat Med 2011; 17: $1235-41$.

44. Manolagas SC. Birth and death of bone cells: basic regulatory mechanisms and implications for the pathogenesis and treatment of osteoporosis. Endocr Rev 2000; 21: 115-37.

45. Yuan YY, Kostenuik PJ, Ominsky MS, Morony S, Adamu S, Simionescu DT et al. Skeletal deterioration induced by RANKL infusion: a model for high-turnover bone disease. Osteoporos Int 2008; 19: $625-35$

46. Koide M, Kobayashi Y, Ninomiya T, Nakamura M, Yasuda H, Arai Y et al. Osteoprotegerin-deficient male mice as a model for severe alveolar bone loss: comparison with RANKL-overexpressing transgenic male mice. Endocrinology 2013; 154: 773-82.
47. Xia WF, Tang FL, Xiong L, Xiong S, Jung JU, Lee DH et al. Vps35 loss promotes hyperresorptive osteoclastogenesis and osteoporosis via sustained RANKL signaling. J Biol 2013; 200: 821-37.

48. Keramaris N, Malliaropoulos N, Padhiar N, King J, Maffulli N. The effect of physical exercise on musculo-skeletal metabolism: a systematic review of the role of RANK/RANKL/OPG Pathway [Abstract]. $3^{\text {rd }}$ European College of Sports and Exercise Physicians (ECOSEP) Conference; 2013 Apr 25-27; Frankfurt. Br J Sports Med 2013; 47: e3. doi: 10.1136/bjsports-2013-092558.38

Received 16 Oct 2014

Revised 17 Jul 2015

Accepted 10 Aug 2015

Published 08 Feb 2016

Online: http://www.mona.uwi.edu/wimjopen/article/1654

(C) Hassan et al 2016 .

This is an open access article made freely available under Creative Commons Attribution 4.0 International (CC BY 4.0). Users are free to share, copy and adapt this work as long as the copyright holder (author) is appropriately and correctly credited. See http://creativecommons. org/licences/by/4.0/deed.en_us for more information. 